\title{
Field tests of a novel solar-assisted dual source multifunctional heat pump Giorgio Besagni ${ }^{1}$, Lorenzo Croci ${ }^{1}$, Riccardo Nesa ${ }^{1,2}$, Luca Molinaroli ${ }^{2}$ and Pietro Quaglia ${ }^{1,2}$ ${ }^{1}$ RSE S.p.A., Power System Development Department, via Rubattino 54, 20134 Milano (Italy) \\ 2 Politecnico di Milano, Department of Energy, via Lambruschini 4a, 20156, Milano (Italy)
}

\begin{abstract}
In this paper, we present the results of field study concerning a novel solar-assisted dual-source multifunctional heat pump, installed in a detached house in Milan. The system couples hybrid photovoltaic/thermal (PVT) panels with multifunctional and reversible heat pump. The proposed system is equipped with an "air source" evaporator and a "water source" evaporator, connected in series and operated alternatively, based on the ambient conditions and system parameters. The "air source" evaporator is an external unit; conversely, the "water source" evaporator is connected with a storage tank, fed by the PVT system. The PVT system is connected with the heat pump by two storage tanks to be used to produce domestic hot water and to be used in "water source" evaporator. Based on the operating conditions, the hot water is sent to one of the storage tank. The proposed system has been tested experimentally; the results show that the system was able to maintain high efficiency in the different seasons and was able to produce domestic hot water. It was found that the use of the "water source" evaporator was able to compensate the performance degradation of the "air source" source evaporator caused by the low ambient temperature.
\end{abstract}

Keywords: Solar assisted heat pump, Hybrid photovoltaic/thermal panels, Dual Source, Domestic hot water, PVT, SAHP

\section{Introduction}

Multifunctional heat pumps are widely used for heating and cooling applications, as well as for the production of domestic hot water $(D H W)$, by exploiting different heat sources (i.e., ground source, air source or water source). In particular, the coefficient of performance $(C O P)$ of air-source heat pumps depends on the ambient temperature, $T_{a m b}$ (viz. $T_{a m b}$ is related to the evaporating temperature, $T_{e v a}$ ). As a consequence, in the winter season, when heating is needed and $T_{a m b}$ is lower, the system performance decreases, owing to the lower evaporating temperature. Conversely, considering a reversible heat pump in the summer season, when cooling is needed and $T_{a m b}$ is higher, the system performance decreases, owing to the higher condensing temperature. In this respect, the coupling between solar technologies and heat pumps-"solar-assisted heat pumps" (SAHPS - is a promising technology to overcome the above-mentioned limitations, to reduce the consumption of energy resources and to meet the targets set by the recent regulations (i.e., European Union targets). Generally speaking, heat pumps can be coupled with photovoltaic $(P V)$ panels, thermal collectors or hybrid photovoltaic/thermal (PVT) panels, as outlined in the literature surveys proposed by Kamel et al. (Kamel, Fung e Dash 2015) and by Mohantaj et al. (Mohanraj, et al. 2017). In practical applications, heat pumps are coupled with thermal or PVT panels, in direct or indirect expansion configurations. In direct expansion SAHP, the solar panel corresponds to the evaporator of heat pump; conversely, in indirect expansion $S A H P$, an intermediate heat exchanger is used to couple the solar system and the heat pump. In addition, SAHP systems can be classified into three sub-categories: (a) parallel systems, (b) series systems and (c) dual-source systems. In parallel systems, the heat pump receives energy from the ambient, and the solar energy is supplied directly for either space heating or for $\mathrm{DHW}$ production. In series systems, solar energy is supplied to the evaporator of the heat pump, thus raising the evaporating temperature (thus, increasing the $C O P$ ) and cooling the solar collectors (thus, increasing the efficiency of the solar panels). In the dual-source systems, the evaporator can receive energy from either the atmosphere or from the solar energy, depending on the ambient conditions and system operation . 
This paper contributes to the existing discussion concerning multifunctional SAHP for heating and cooling applications, as well as for the production of $D H W$. In the last decades, different systems have been proposed and, in the following, a brief literature survey is proposed to better outline the framework of this research. Wang et al. (Wang, et al. 2011) experimentally investigated, in a laboratory-scale experimental setup, an indirect dualsource ("air-source" and "water-source" evaporators) SAHP for space heating and cooling and water heating. A storage tank, connected to thermal panels, was used to supply heat to the "water-source" evaporator or to produce $D H W$. They reported $C O P=4$, in the heating mode. Bridgeman and Harrison (Bridgeman e Harrison 2008) experimentally investigated, in a laboratory-scale experimental setup, the performance of an indirect series $S A H P$ for water heating. They observed $C O P=2.8-3.3$, depending on the evaporator and condenser temperatures. Loose et al. (Loose, et al. 2011) performed field tests of various combined SAHP systems with different heat sources, for space heating and water heating. The system employed solar thermal collectors and geothermal heat pump with borehole heat exchangers. The collectors fed the storage tank directly when the sufficient solar radiation was available. Otherwise, low grade energy from the collectors would be used in the heat pump for space heating. Bakirci et al. (Bakirci e Yuksel 2011) investigated the performance of an indirect SAHP system for space heating. The solar collectors directly charged a storage tank which was linked to an evaporator to provide a heat source for the heat pump. They observed COP in the range of 3.3 - 3.8. Bai et al. (Bai, et al. 2012) theoretically studied, by using a TRNSYS model, an indirect combined hybrid PVT SAHP system for $D H W$ production. Year round performance results were simulated under the different climatic conditions (Hong Kong and different locations in France) and an average $C O P=4.9$ has been observed.

From the above-mentioned literature survey, as well as from the literature surveys proposed by different authors (Hepbasli e Kalinci 2009, Ozgener e Hepbasli 2007, Parida, Iniyan e Goic 2011, Tian e Zhao 2013), it is observed that there is a lack of field studies concerning practical demonstration and fields studies concerning multifunctional dual source ("air-source" and "water-source" evaporators) SAHP. To this end, this paper presents the field tests of a novel solar-assisted dual-source multifunctional heat pump, installed in a detached house in Milan. The system couples hybrid PVT panels with a multifunctional and reversible heat pump. The paper is organized as follows. First, the experimental setup and methods are presented and described; second, the experimental results are commented and discussed; finally, main conclusions are drawn

\section{Experimental setup and methods}

In this section, the experimental setup and the experimental methods are presented and described. First, the multifunctional heat pump system and main characteristic of the components are presented and discussed (Section 2.1). Second, the details concerning the operation procedures are outlined (Section 2.2). Finally, the experimental techniques (Section 2.3) and performance parameters (Section 2.4) are described and commented.

\subsection{Experimental setup}

The multifunctional heat pump system (Fig. 1) has been designed and installed in a detached house (Fig. 2) located in Milan, at RSE Spa headquarter. The detached house has an heating/cooling area equal to $64 \mathrm{~m}^{2}$, with a nominal load equal to $4 \mathrm{~kW}_{\text {th }}$ (indoor temperature equal to $20^{\circ} \mathrm{C}$ and outdoor temperature equal to $-5{ }^{\circ} \mathrm{C}$ ). Fig. 1 displays the layout of the multifunctional heat pump, which is composed by five parts: (a) a solar system, (b) a DHW storage tank and an "intermediate-temperature" storage tank, (c) a reversible heat pump, (d) terminal heating and cooling systems (viz. fan coils) and (e) circulating pumps (Tab. 1). Further details concerning the different components of the system are provided in the following.

Solar system. The solar system consists in seven $P V T$ panels and a $P V$ panel (Fig. 2). The $P V$ panel has the same size and cells characteristic of the $P V T$ panels, to compare the performance of the two technologies. The seven $P V T$ panels (south-oriented, $45^{\circ}$ titled angle) have $1.75 \mathrm{~kW}_{\mathrm{el}}$ nominal power and are of the roll-bond technology (Fig. 3a). They are composed by polycrystalline silicon cells, a steel heat-exchanger and a $0.002 \mathrm{~m}$ insulation. In the heat exchanger part of the $P V T$, water/ethylene glycol mixture has been used as working fluid, to prevent icing-related issues, with a nominal flow rate equal to $0.630 \mathrm{~m}^{3} / \mathrm{h}$. It is worth noting that the comparison between $P V$ and $P V T$ panels is not presented here and is a matter of ongoing research activities.

Storage tanks. The $D H W$ storage tank $\left(0.186 \mathrm{~m}^{3}\right.$ in volume $)$ has been used to produce hot water; conversely, the "intermediate-temperature" storage tank $\left(0.300 \mathrm{~m}^{3}\right.$ in volume, Fig. $\left.3 \mathrm{~b}\right)$ has been used as "water-source" from the heat pump, instead of the "air-source" one, to improve the performance in cold days and avoid defrosts and 
reduce temperature fluctuations. Inside the "intermediate-temperature" storage tank water/ethylene glycol mixture has been used as working fluid, to prevent icing-related issues. The "intermediate-temperature" is connected to the heat pump, by a plate heat exchanger (Fig. 3c) and the maximum flow rate "intermediatetemperature" towards the "water-source" heat exchanger is $1.45 \mathrm{~m}^{3} / \mathrm{h}$.

Heat pump unit. The heat pump is a $\mathrm{R} 410 \mathrm{~A}$ reversible heat pump, $7 \mathrm{~kW}$ th nominal heating capacity and 3.47 nominal COP (water leaving temperature equal to $35^{\circ} \mathrm{C}$ and air temperature equal to $7{ }^{\circ} \mathrm{C}$ ), equipped with an electronic expansion valve and a variable speed compressor.

Circulating pumps. As shown in Fig. 1, the experimental system includes circulating loops: (a) solar collector loops; (b) "intermediate-temperature" storage tank to heat pump; (c) indoor terminal fan-coil side loop and (d) $D H W$ circulating loops. Details on pumps used are provided in Table 1.

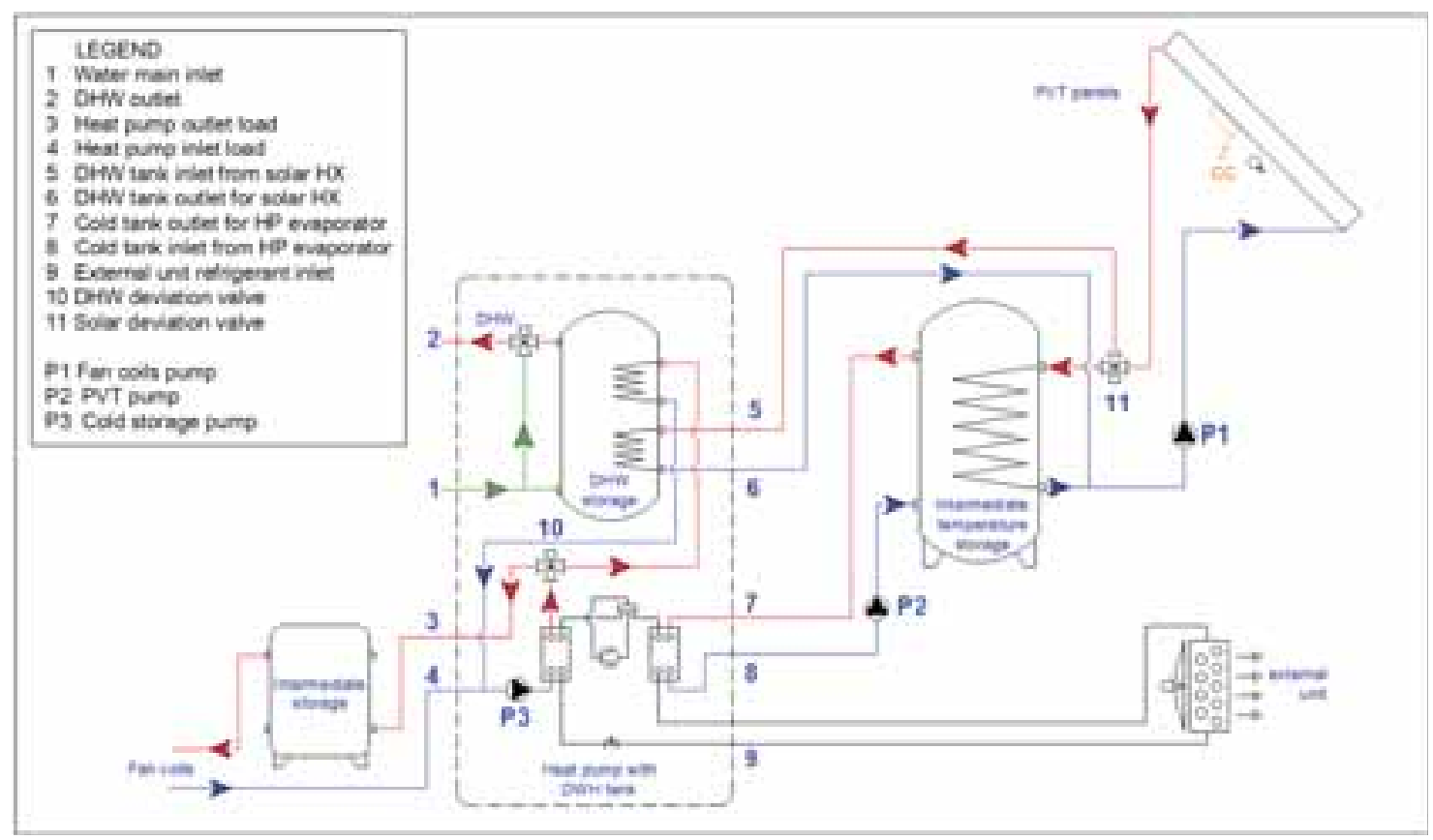

Fig. 1: Experimental layout

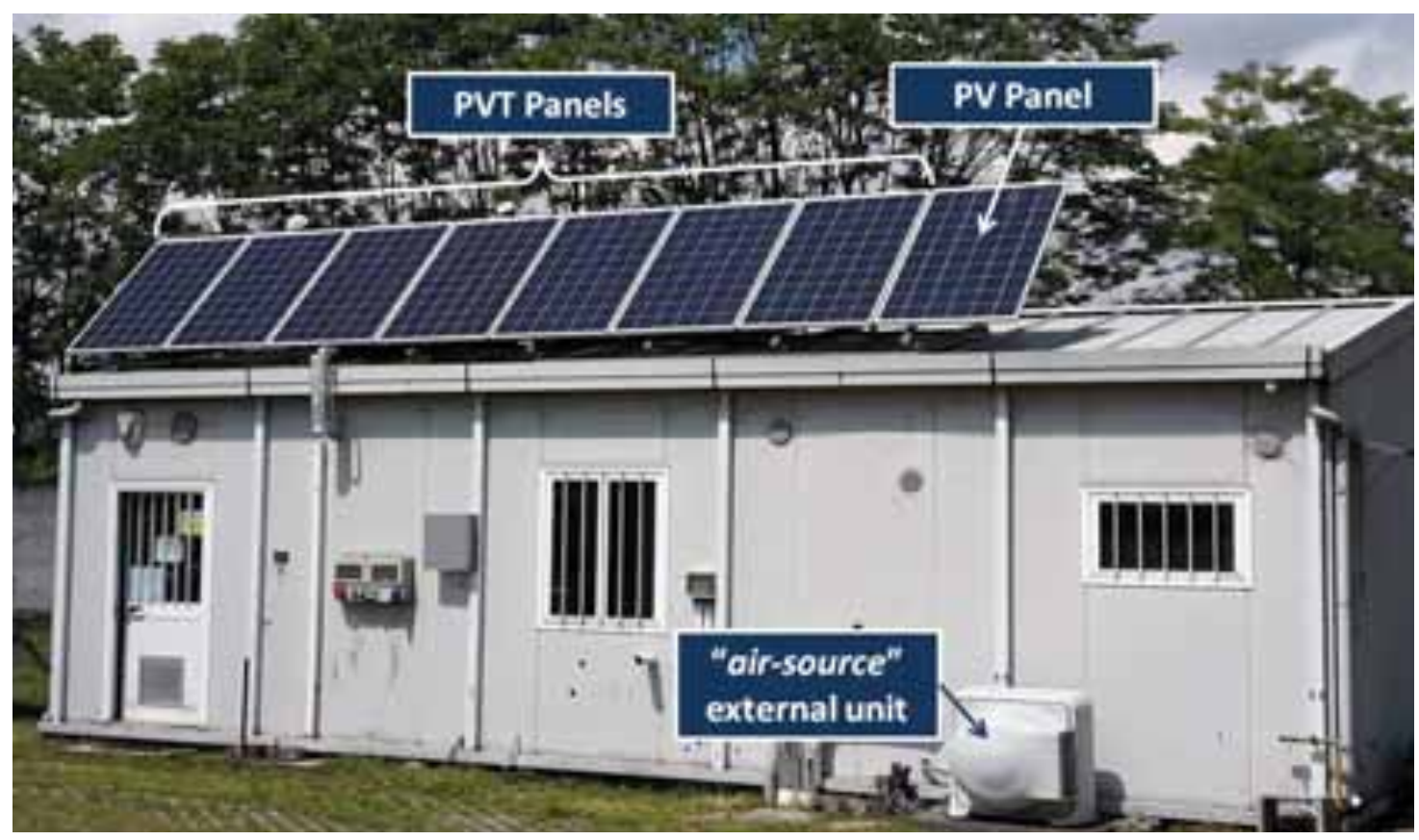

Fig. 2: Photo of the detached house at RSE Spa 


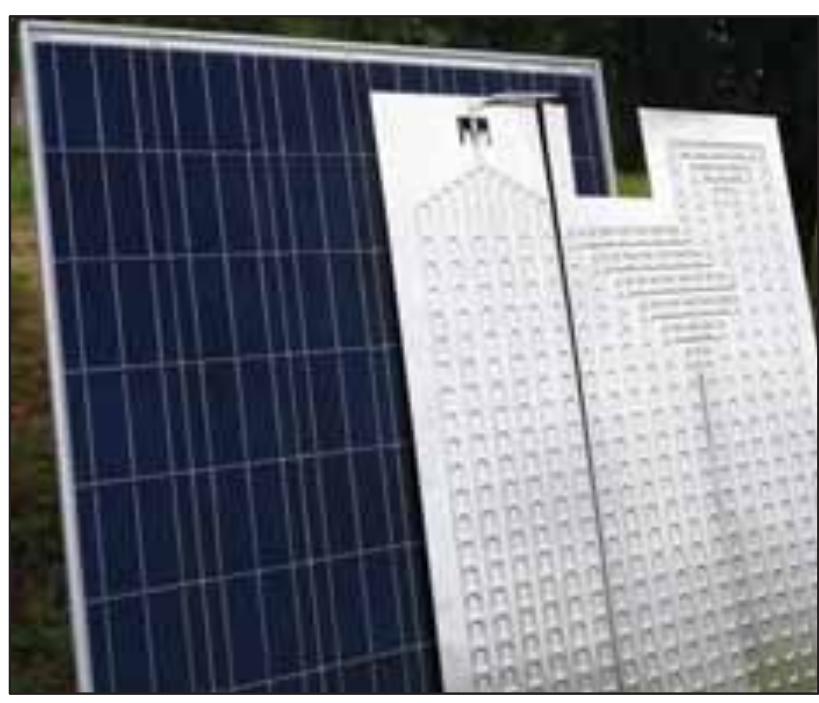

(a) PVT roll-bond panels

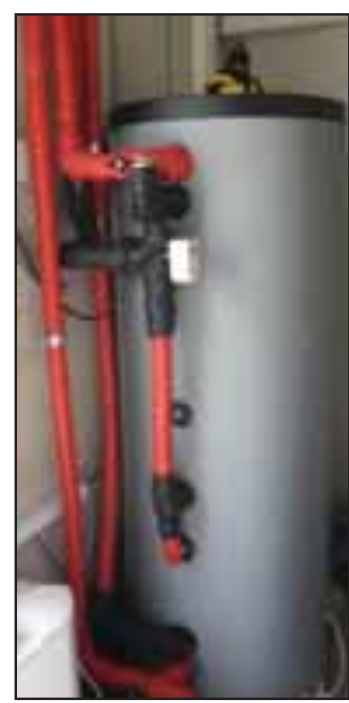

(b) "intermediate-temperature" tank

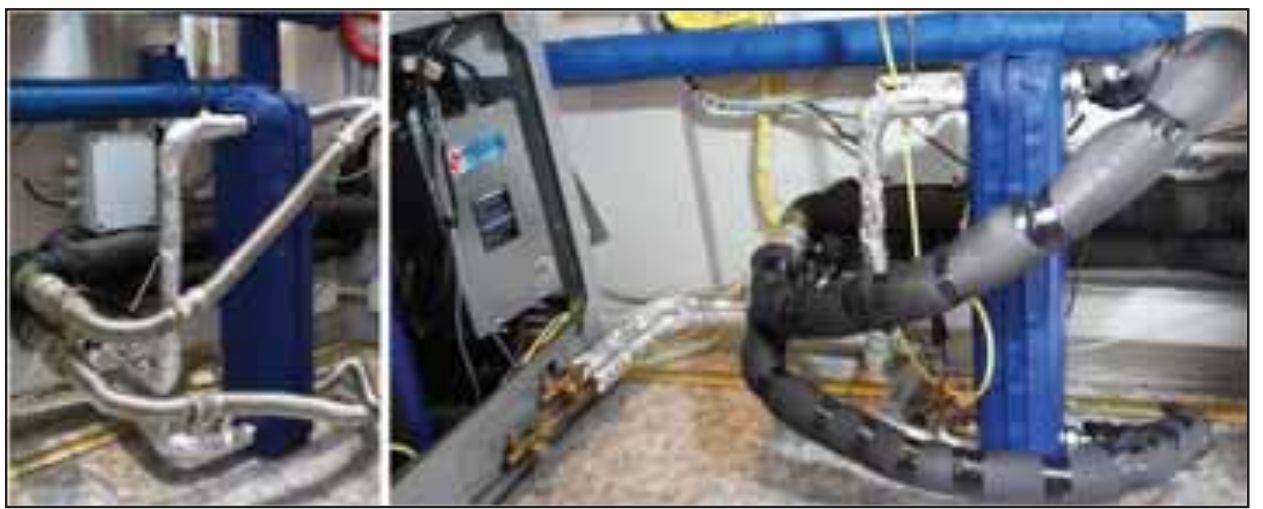

(c) Plate heat exchanger between the heat ump and the "intermediate-temperature" tank

Fig. 3: Details of the experimental setup

Tab. 1: Details on circulating pumps used (see Fig. 1 for further details)

\begin{tabular}{|c|c|c|c|}
\hline Code (Fig.1) & Location & Technical details & Power [W] \\
\hline$P 1$ & Solar circulating pump & DEB Evolplus Small 60/180 M PWM & $5-100$ \\
\hline$P 2$ & "intermediate temperature" circulating pump & WILO Stratos Para 25/1-7 PWM & $5-70$ \\
\hline$P 3$ & Fan-coil circulating pump & WILO Stratos TEC RS 25/7 PWM & $3-70$ \\
\hline$P 4$ & $D H W$ circulating pump & WILO ZRS 12/7 & 86 (fixed speed) \\
\hline
\end{tabular}

\subsection{Operation modes and control}

The multifunctional heat pump has been tested starting from $17^{\text {th }}$ January 2017 and the monitoring is still ongoing. The system has been tested in three operation modes in order to study the influence of the different operation parameters; each mode was controlled aiming to (a) minimize the electricity consumption by the heat pump, using solar thermal energy, and (b) maximizing the production of electricity of $P V T$ panels keeping their operating temperature as low as possible. The operating principles for each mode are provided in the following.

- Mode\#1. Heating mode without $\mathrm{DHW}$ production (from 17/01/2017 to 13/03/2017). The internal set-point temperature was set at $T_{\text {set-point }}=22{ }^{\circ} \mathrm{C}$, with night attenuation of $4{ }^{\circ} \mathrm{C}$ (from 22.00 to 7.30 ). In this operation mode, the temperature of the water produced by the heat pump and sent to the fan-coils was set by using a climatic curve: $T_{3}=43{ }^{\circ} \mathrm{C}$ with $T_{a m b}=0{ }^{\circ} \mathrm{C}$ and $T_{3}=35^{\circ} \mathrm{C}$ with $T_{a m b}=15^{\circ} \mathrm{C}$. In this 
operation mode, valve $V 1$ was set to deviate all thermal energy produced by the PVT panels to the "intermediate-temperature" storage tank. The "intermediate-temperature" storage tank, is used as the "water-source" for the heat pump when $T_{a m b}$, is low and the resulting COP would decrease. Changes from "air-source" evaporator to "water-source" evaporator are obtained by switching on/off the pump $P 2$ and switching on/off the external "air-source" unit.

- Mode\#2. Heating mode with $\mathrm{DHW}$ production (from 13/03/2017 to $24 / 05 / 2017$ ). The operation mode mode\# 1 has been modified as follows: (a) a daily profile of $D H W$ production was set to produce $150 l$ (corresponding to, approximately, $4 \mathrm{KWh}$ ); (b) valve $V 1$ was set to deviate the glycol-water mixture, at the outlet of the PVT panels, depending on the temperature of the storage tanks (a) towards the "intermediate-temperature" $D H W$ storage $\left(T_{\text {intermediate-temperature }}<38^{\circ} \mathrm{C}\right)$, (b) towards the $D H W$ tank ( $T_{\text {intermediate-temperature }} \geq 38{ }^{\circ} \mathrm{C}$ ) or towards the "intermediate-temperature" storage $\operatorname{tank}\left(T_{D H W, \text { tank }} \geq 58{ }^{\circ} \mathrm{C}\right)$; (c) the $D H W$ storage tank set-point temperature was set to $T_{D H W \text {,set-point }}=48^{\circ} \mathrm{C}$ and its lower temperature has been set $T_{D H W \text {,mantenance }}=42^{\circ} \mathrm{C}$. In the case, the temperature of the $D H W$ storage tank would fall below $T_{D H W \text {,mantenance }}$, the heat pump would be used been used to increase the $D H W$ tank temperature.

- Mode\#3. Cooling mode with $\mathrm{DHW}$ production (from 24/05/2017, ongoing). The internal set-point temperature was set at $T_{\text {set-point }}=24{ }^{\circ} \mathrm{C}$. In addition, the operation mode mode\#2 was modified as follows: (a) a daily profile of $\mathrm{DHW}$ production has been set to produce $150 l$ (corresponding to approximately, $3 \mathrm{KWh}$; the DHW corresponding power is lower compared with the previous operation mode, owing to the higher inlet water temperature, $T_{1}$ ); (b) valve $V 1$ was set to deviate the glycol-water mixture, at the outlet of the PVT panels, depending on the temperature of the storage tanks towards the $D H W$ storage tank $\left(T_{\text {intermediate-temperature }} \geq 36^{\circ} \mathrm{C}\right.$ ) or towards the "intermediate-temperature" storage tank $\left(T_{D H W, t a n k} \geq 57^{\circ} \mathrm{C}\right) ;$ ).

\subsection{Measurement system and procedure}

All the main variables, to describe mass and energy balances, have been measured. The flow rate in each circuit has been measured by an electromagnetic flowmeter meter (E\&H Promag P50, $\pm 0.2 \%$ read value). All the inlet and outlet temperatures of the main equipments, the supply and return water temperatures of the different locations, were measured by RTD Pt100 4wire 1/5DIN, inserted inside the pipes. The indoor and outdoor (near the PVT panels) temperature and humidity were measured by an Pt100 4wire hygrometer (Siap+Micros). The solar radiation intensity has been measured by a thermopile pyranometers (pyranometer Kipp\&Zonen CMP11), mounted at a $45^{\circ}$ inclined angle near the PVT panels. The power consumption of the heat pump and the circulating pumps (solar pumps, intermediate-storage tank, fan-coil pump) were measured by multifunction electric meters (Shark 100, $\pm 0.1 \%$, and FRER MonoNano, $\pm 0.5 \%$ ). Evaporating and condenser pressures were measured by pressure transducers (Keller series 21Y). All the temperature probes were verified with a calibration procedure by using thermostatic batch, at RSE Spa. All data were recorded automatically at every 6 seconds interval in a data logger (Advantech ADAM 5000 and 4000 data logging devices) to be further postprocessed.

\subsection{Performance evaluation}

The performance of the system has been evaluated based on the mass and energy balances, based on the recorded data (flow rates and temperatures). In particular, the energy fluxes across every component has been computed as follows:

$$
Q=\dot{m} c_{p}\left(T_{\text {inlet }}-T_{\text {outlet }}\right)
$$

In Eq. (1), $T_{\text {inlet }}$ and $T_{\text {outlet }}$ refer to the inlet and outlet temperatures, $m$ is the mass flow rate, $c_{p}$ is the specific heat of water. Based on the heat fluxes and the electric power measured, the COP (during heating mode; mode\#1 and mode\#2, Eq. (2)) and the EER (during the cooling mode; mode\#3, Eq. (3)) have been computed as follows:

$$
\begin{aligned}
C O P & =\frac{Q_{H P \rightarrow \text { fan-coil }}+Q_{H P \rightarrow D H W-t a n k}}{P_{e l}} \\
E E R & =\frac{Q_{H P \leftarrow \text { fan-coil }}+Q_{H P \rightarrow D H W-\text { tank }}}{P_{e l}}
\end{aligned}
$$


In Eqs. (2-3), $P_{e l}$ is the electric power provided to the systems; $Q_{H P \rightarrow \text { fan-coil }}$ and $Q_{H P \leftarrow \text { fan-coil }}$ is computed based on $T_{3}$ and $T_{4}$ and $m_{3}=m_{4}$ (please refer to Fig. 1 for the location of the subscripts) and refer to the heat transfer from the heat pump towards the fan-coils and vice-versa; conversely, $Q_{H P \rightarrow D H W-t a n k}$ refers to the het flux provided from the heat pump to the $\mathrm{DHW}$ tank and is computed as follows:

$$
Q_{H P \rightarrow D H W-\text { tank }}=\sum_{t=0}^{n=N} \rho V_{D H W, \operatorname{tank}} c_{p}\left(T_{t=n}-T_{t=n-1}\right)
$$

In Eq. (4), $V_{D H W, t a n k}$ is the volume of the $D H W$ tank, $\rho$ is the density of water, and $t$ is the time variable. Please note that Eq. (4) is computed under the following constrains: (a) the temperature of the $D H W$ storage is below $T_{D H W \text {,maintenance }}$ (b) the temperature of the $D H W$ storage tank is increasing with time; (c) heat pump status is ON.

To study the influence of the "water source" evaporator and the "air-source" evaporator, Eq. (2) has been modified as follows, based on the status of the storage tank circulating pump (pump P2, Fig. 1):

$$
\begin{aligned}
& C O P \text { "water-source" }=\frac{Q_{H P \rightarrow \text { fan-coil }}+Q_{H P \rightarrow D H W-\text { tank }}}{P_{e l}} \text { if pump } P 2=O N \\
& C O P \text { "air-source" } \\
& =\frac{Q_{H P \rightarrow \text { fan-coil }}+Q_{H P \rightarrow D H W-\text { tank }}}{P_{e l}} \text { if pump } P 2=\text { OFF }
\end{aligned}
$$

\section{Experimental results}

In this section, the experimental results are presented and discussed. First, the ambient conditions in the monitored period are presented. Second, the performance of the heat pump are presented and commented with reference to the three different operating modes. Finally, the influence of the "water-source" and the "airsource" evaporators on the performance are commented.

\subsection{Ambient conditions}

In order to provide an overview of the heat pump working conditions, Fig. 4 displays the value of ambient conditions in the monitored period. In particular, Fig. 4 displays the daily averaged values of the ambient temperature and relative humidity. It is worth noting that the heat pump was operated in a quite broad range of operating conditions (i.e., daily averaged $T_{a m b}$ ranged between 0 and $33{ }^{\circ} \mathrm{C}$; conversely, the instantaneous values of $T_{a m b}$ ranged between $-5^{\circ} \mathrm{C}$ and $40^{\circ} \mathrm{C}$ ).

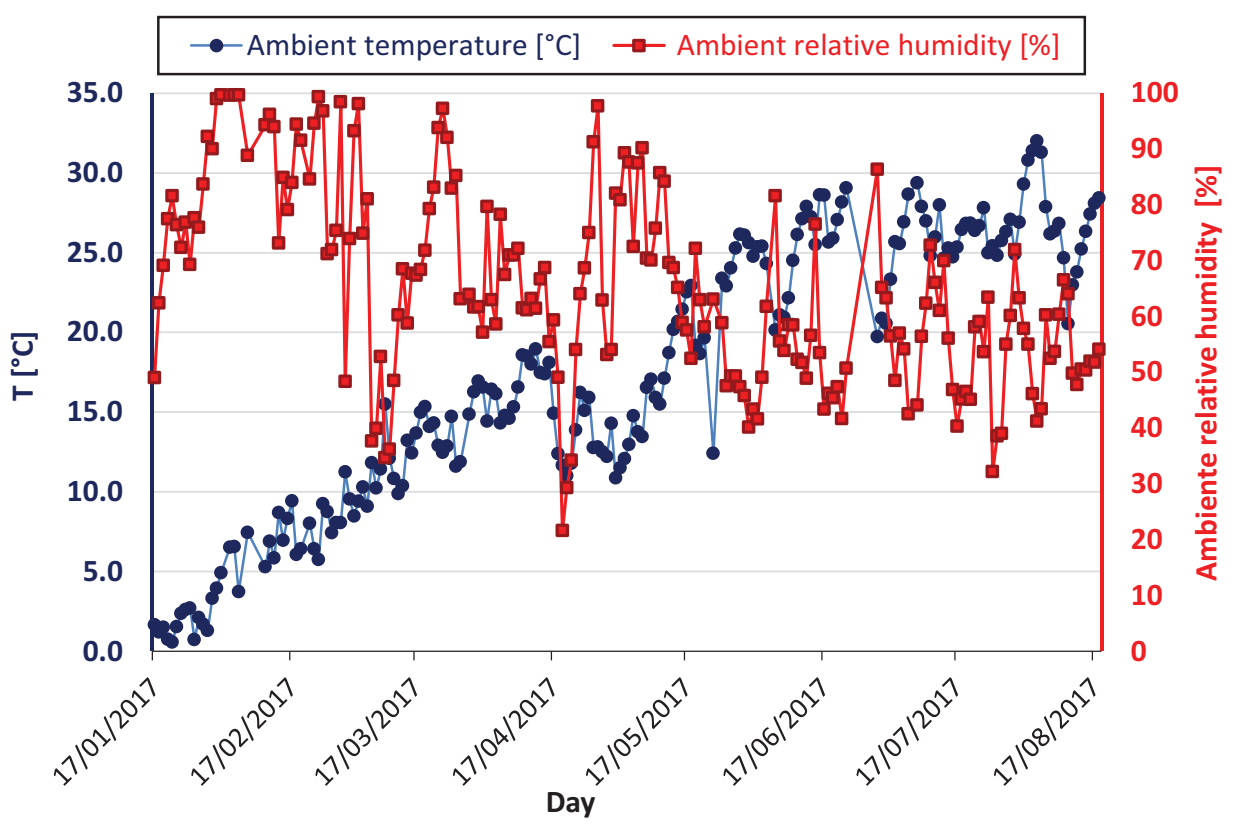

Fig. 4: Daily-averaged ambient conditions: ambient temperature and relative humidity 


\subsection{Seasonal performance}

Fig. 5 displays the daily-averaged performance of the multifunctional heat pump in the three operating modes described in Section 2.2. In addition, in Fig. 5, $T_{a m b}$ is displayed for the sake of clarity. The performance of the multifunctional heat pump are computed by using Eq. (2)—the COP-and Eq. (3)-the EER. In the operation mode\#1, the useful effect of the heat pump is $Q_{H P \rightarrow \text { fan-coil }}\left(\right.$ there is no $D H W$ production; $Q_{H P \rightarrow D W H \text {-tank }}=0$ ); conversely, in the other operation modes (viz. mode\#2 and mode\#3) the useful effect of the heat pump consists in both $Q_{H P \rightarrow f a n-c o i l}$ and $Q_{H P \rightarrow D W H \text {-tank }}$. Please note that the electric consumption, $P_{e l}$, considered in the evaluation of $C O P$ and EER does not account for the contribution of the auxiliaries (i.e., circulation pumps, stand-by consumption, etc...): (a) the solar circulating pump (its consumption was approximately $4.1 \%$ of the total energy consumption); (b) the "intermediate-temperature" circulating pump (its consumption was approximately $1.2 \%$ of the total energy consumption); (c) the Fan-coil circulating pump (its consumption was approximately $3.7 \%$ of the total energy consumption), (d) the DHW circulating pump and all other auxiliaries (their consumptions were approximately $14.2 \%$ of the total energy consumption).

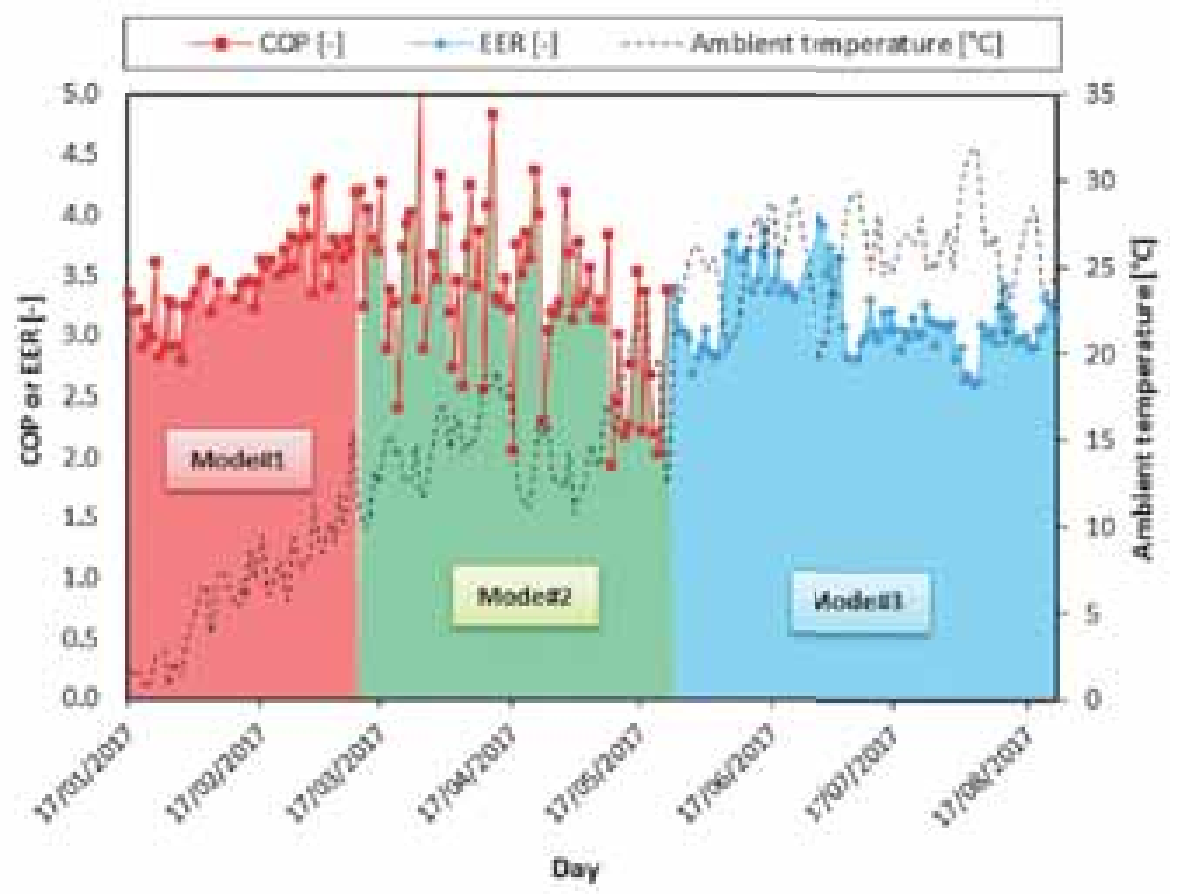

Fig. 5: Daily-averaged performance of the multifunctional heat pump depending on the operation mode and ambient temperature

In the operation mode mode\#1, the daily-averaged COP is in the range of 3 and 4.5; as expected, COP increases with time, owing to the increasing daily-averaged $T_{a m b}$. The relationship between $T_{a m b}$ and the heat pump performance can be further understood, by considering the layout of the system. Indeed, the performance of an heat pump may be related (for fixed component design), to the evaporating and condensing temperatures/pressures. In the present case: (a) the condensing pressure is related to the internal conditions, that, for a fixed set-point are periodical with time; (b) evaporating temperature $T_{\text {eva }}$ is related to $T_{a m b}$, owing to the variable speed compressor and the electronic expansion valve. Therefore, a variation in the ambient temperature, mainly affects $T_{\text {eva }}$ and, thus, affect the performance of the system. To better discuss this concept, Fig. 6 displays the relationship between the variables of the heat pump (i.e., evaporator pressure and condensing pressure), $T_{\text {eva }}$ and COP. The reader may refer to the studies proposed by Kuang and Wang (Kuang e Wang 2006) and Ma and Zhao (Ma e Zhao 2008) for a more detailed discussion on the role of variable speed compressors in heat pumps. In addition, in Fig. 6 is also displayed the influence of the "water-source" evaporator. This point is further discussed in Section 3.3. In the operation mode mode\#2, the performance of the system, compared with mode\#1, shows a larger variability and are slightly lower. This behavior can be explained based on the system operations as well as on the ambient conditions. First, in this period, beside DHW production, $Q_{H P \rightarrow \text { fan-coil }}$ is very low and, in some days, $Q_{H P \rightarrow \text { fan-coil }} \approx 0$, owing to the high $T_{a m b}$ (the internal set-point temperature can be achieved also with very low heat pump load). Therefore, $C O P$ is mostly related to $Q_{D H W-t a n k}$. Second, it should be noted that 
$Q_{H P \rightarrow D H W-t a n k}$ is produced at higher temperature compared with $Q_{H P \rightarrow \text { fan-coil }}$; therefore the expected performance of the heat pump is reduced. In this respect it is well known that Eq. (2) does not take into account the grade of heat produced, as it is related to energy balances and neglect the entropy/exergy concept. In the operation mode mode\#3, in the cooling mode with DHW production, the daily-averaged EER is in the range of 3 and 4.5. The discussion concerning the relationship between the ambient conditions and the system performance is similar to the above-discussion for the operation mode mode\#1. It is worth noting that, owing to the high ambient temperature, in the summer season, the PVT panels are able to contribute to the maintenance temperature of the $D H W$ storage tank, thus reducing $Q_{H P \rightarrow D H W \text {-tank }}$ and, thus, the energy consumption of the heat pump.

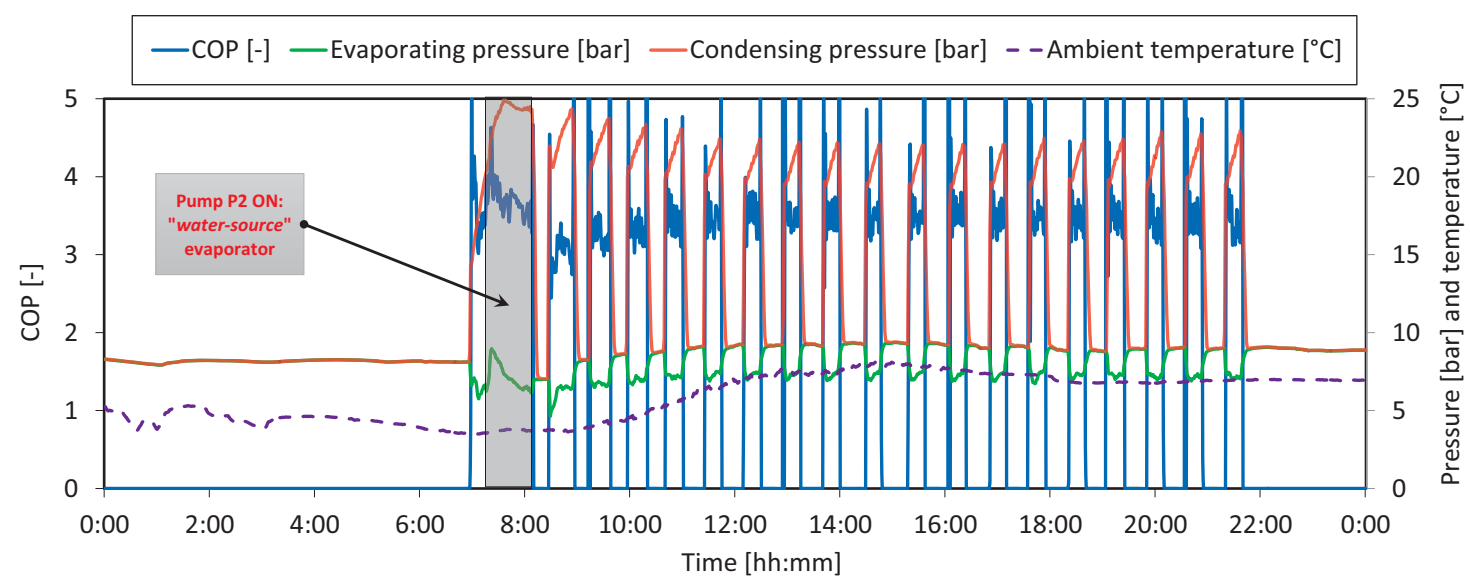

Fig. 6: Daily performance of the multifunctional heat pump: performance parameters (data obtained at 13/02/2017, mode\#1)

\subsection{Comparison between water source and air source}

In this section, an insight in the performance of the system is proposed, by analyzing the contribution of the "water-source" evaporator and the "air-source" evaporator to achieve the averaged performance described in Section 3.2. To this end, by applying Eqs. (5-6) in the in the operation mode mode\#1, the corresponding "watersource" the "air-source" performances have been obtained; the results of this analysis have been summarized in Fig. 7, in terms of daily-averaged values. Please note that in some days (viz. the data not displayed in Fig. 7), the "water-source" evaporator was not used. Applying the whole dataset, (in the operation mode\#1) and applying Eqs. (5-6), an average COP increase approximately 35.5\% from the "air-source" mode to the "water-source" mode has been observed. In order to better understand the relationship between "water-source"/"air-source" evaporators and the COP, Fig. 8 proposes three daily profiles of the heat pump operation.

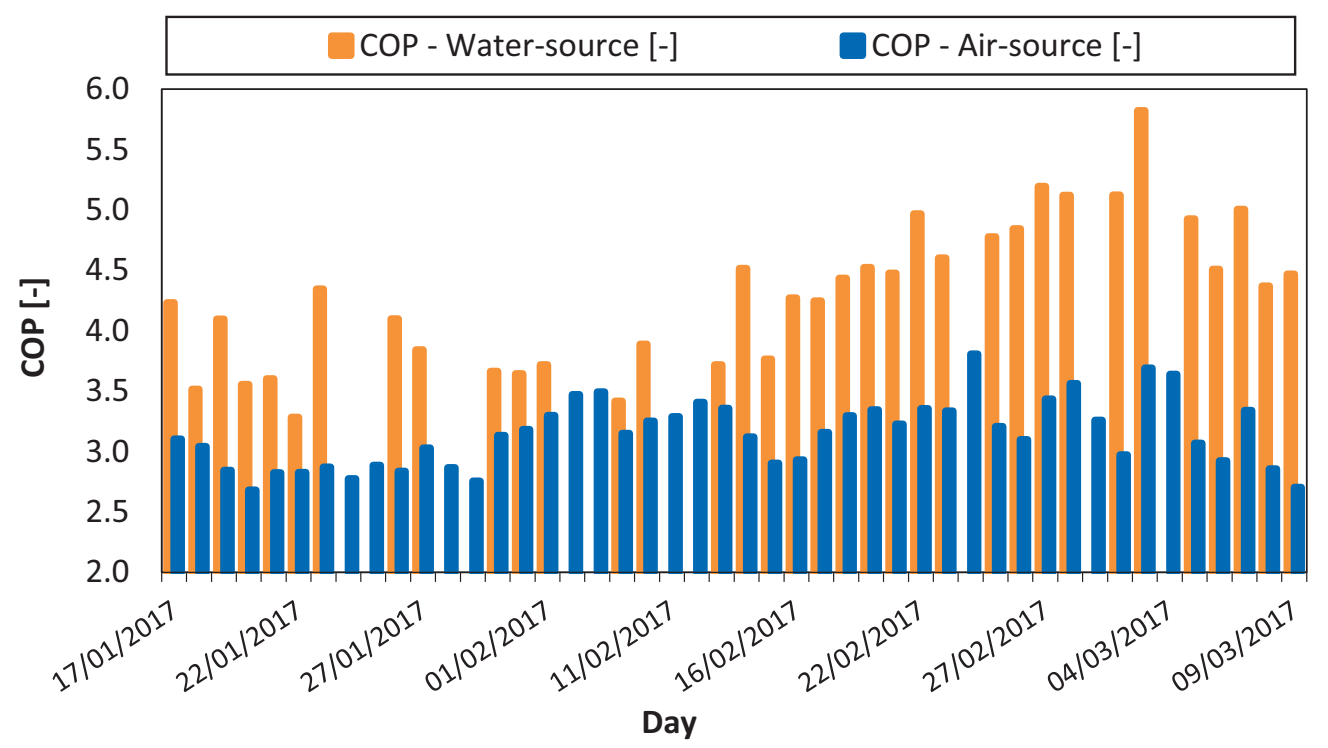

Fig. 7: Daily-averaged performance of the multifunctional heat pump: influence of "water-source" and "air-source" evaporators (data obtained during operation mode mode\#1) 


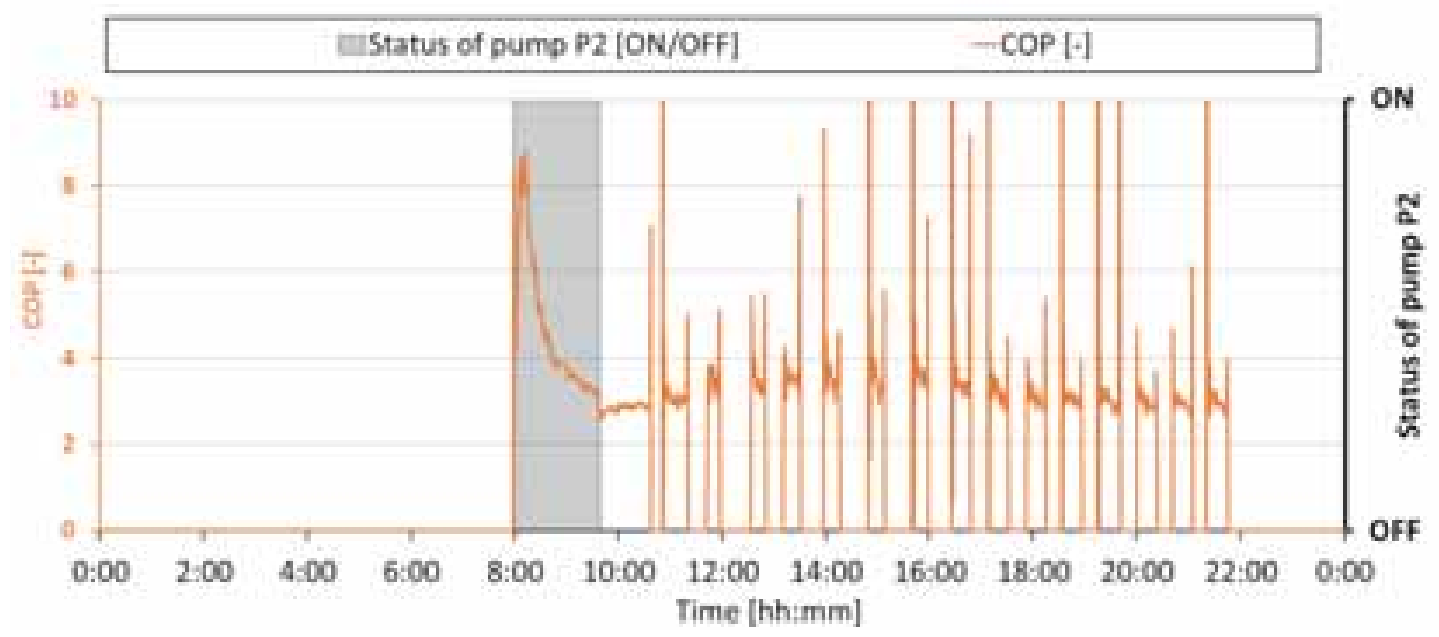

(a) data obtained at 17/01/2017, operation mode mode\#1

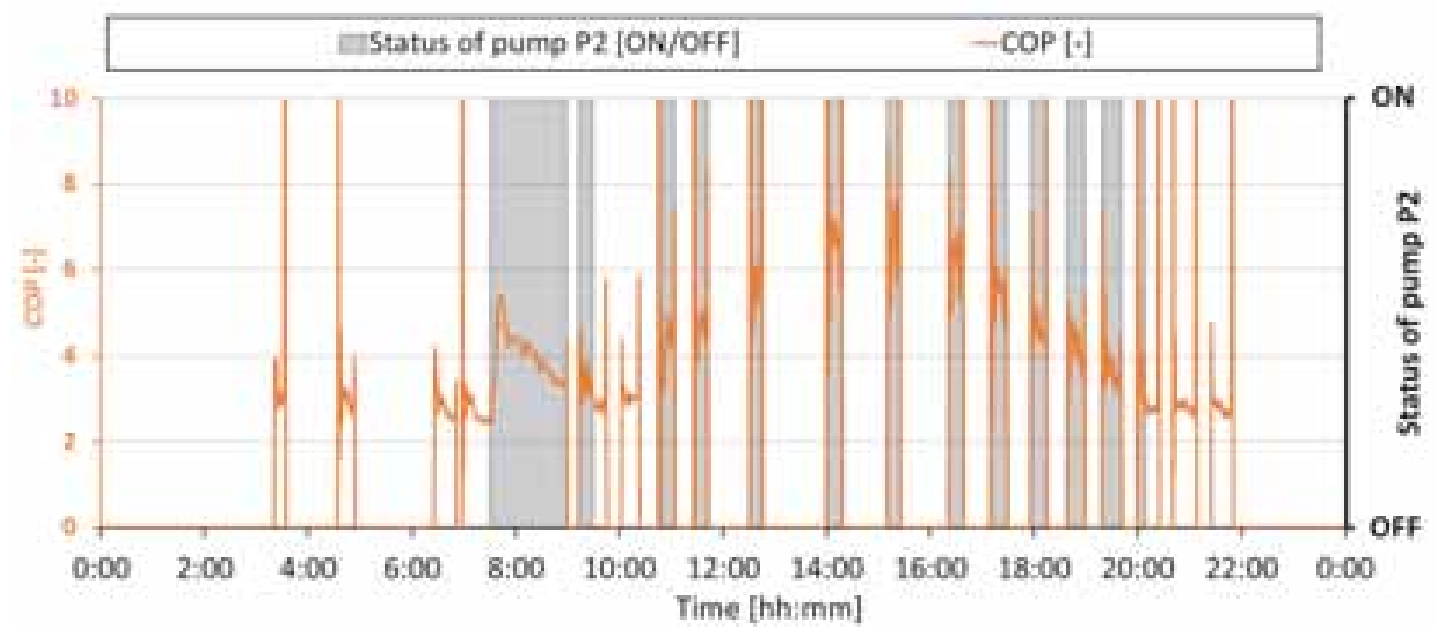

(b) data obtained at 23/01/2017, operation mode mode\#1

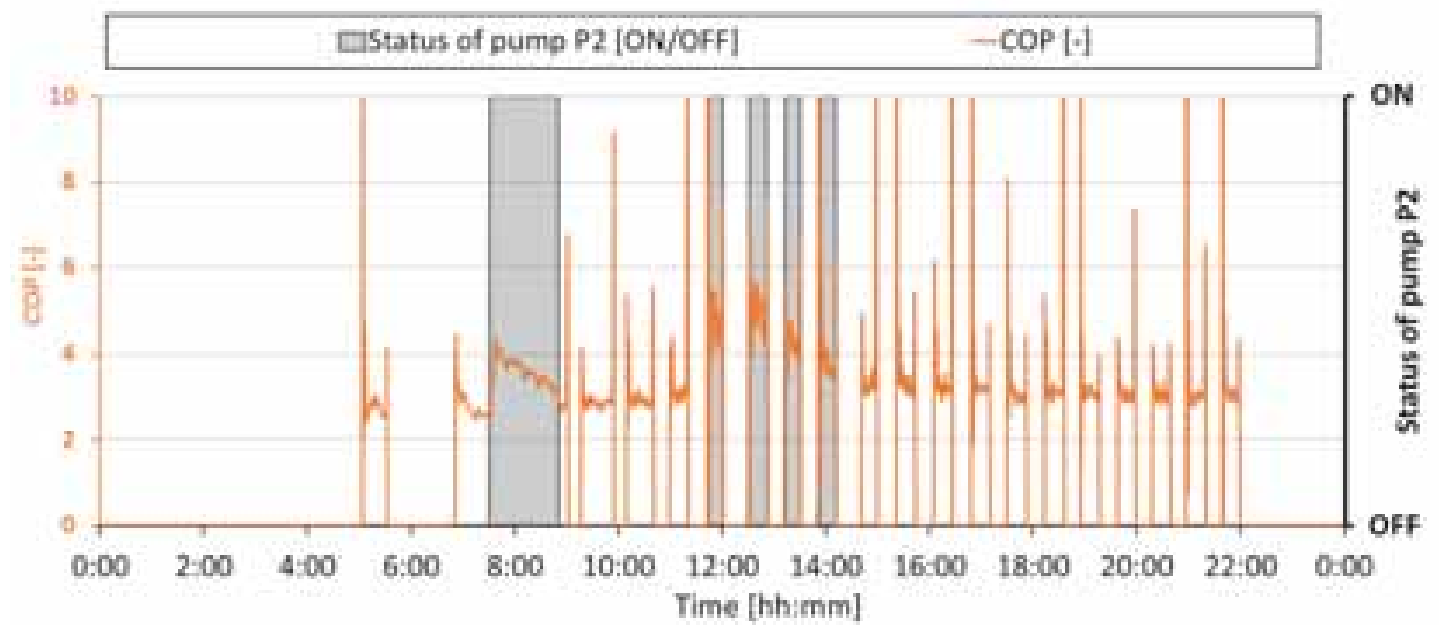

(c) data obtained at 27/01/2017, operation mode mode\#1

Fig. 8: Daily performance of the multifunctional heat pump: influence of "water-source" and "air-source" evaporators 
Fig. 8 clearly displays the significant increase of $C O P$, owing to the use of the "water-source" evaporator. For example, it can be observed that, in Fig. 8a, by activating the pump $P 2$ at 8.00 AM the COP increases from 2.7 to 8 (instantaneous values). Similar considerations can be drawn for the other days displayed in Fig. $8 \mathrm{~b}$ and Fig. 8c. It is important to emphasize that the "water-source" evaporator avoided the defrost cycles of the aerothermal heat pumps and the subsequent decrease in the performances. In this respect, the reader may refer to the defrostrelated issues described by Zhang et al. (Zhang, et al. 2017). It should be noted that the COP obtained using water as source has been obtained in the most unfavorable conditions: the morning, when maximum building load and with the highest delivery water temperature. Unfortunately, the use of the water source is limited in time and depends on the thermal energy available in the "intermediate-temperature" storage tank. Future studies should be focused on alternative technical solutions for storage tanks (i.e., phase change material, $P C M$, storage tanks), to improve the availability of the "water-source".

\section{Conclusions, outcomes and outlooks}

This paper presented the very first results of field study concerning a novel solar-assisted dual-source multifunctional heat, installed in a detached house in Milan. The system couples PVT panels with a dual-source ("air source" and "water source" evaporators) multifunctional and reversible heat pump. The multifunctional heat pump has been tested starting from $17^{\text {th }}$ January 2017 (the monitoring is still ongoing) in three operation modes: (a) heating mode without $D H W$ production; (b) heating mode with $D H W$ (150 1) production; (c) cooling mode with $D H W(150$ l) production.

\subsection{Conclusions and outcomes}

The main results of the filed study are as follows:

- the averaged performance (COP and EER) of the multifunctional heat pump is approximately 3, in the three different operation modes;

- the thermal energy produced by the PVT panels have been successfully used to support the "watersource" evaporator in the winter/spring seasons;

- $\quad$ the thermal energy produced by the PVT panels have been successfully used to support the production of $D H W$ in the summer period;

- the use of "water-source" evaporator allows to significantly increase the performance of the plant;

- the use of "water-source" evaporator allows to avoid defrost cycles;

\subsection{Outlooks}

Ongoing research as well as future studies may concern both experimental and numerical researches. On the experimental part, outlooks are as follows:

- extent the field study to the autumn ambient conditions, to provide a complete seasonal overview of the system operation;

- relate the daily and the seasonal operations, to provide a multi-scale evaluation of the heat pump performance;

- $\quad$ propose a comprehensive thermodynamic evaluation (energy and exergy evaluation) of the whole system;

- compare the performance of PV and PVT systems and provide insights in the relationships between operating conditions (i.e., temperatures, flow rates, ambient conditions) and the panels performances (i.e., thermal and electrical energy production);

- $\quad$ study alternative technical solutions for storage tanks (i.e., phase change material, PCM, storage tanks), to improve the availability of the "water-source".

On the numerical part, future studies would concern the testing and validation of a TRNSYS approach, to extend the results of the present experimental study to different climatic conditions and, finally, to assess the economic feasibility of the proposed system. 


\section{Nomenclature and abbreviation list}

\subsection{Acronyms}

COP

$D H W$

EER

$H P$

PV

PCM

$P V T$

SAHP

\subsection{Symbols}

$c_{p}$

$m$

$N$

$Q_{H P \rightarrow D W H-t a n k}$

$Q_{H P \leftarrow \text { fan-coil }}$

$T$

$t$

$V_{\text {DHW,tank }}$

$V_{\text {DHW,tank }}$

$\rho$

\subsection{Subscripts}

$a m b$

el

eva

inlet

outlet

th
Coefficient of performance

Domestic hot water

Energy Efficiency Ratio

Heat Pump

Photovoltaic

Phase Change Material

Hybrid thermal-photovoltaic

Solar-assisted-heat pump

Specific heat of water

$[\mathrm{kJ} / \mathrm{kg} \mathrm{K}]$

Mass flow rate

$[\mathrm{kg} / \mathrm{s}]$

Time discretization in Eq.

(4)

$[-]$

$[\mathrm{kW}]$

$[\mathrm{kW}]$

Heat transfer from the heat pump to the fan-coils

$\left[{ }^{\circ} \mathrm{C}\right]$

Temperature

[min]

Time in Eq. (4)

$\left[\mathrm{m}^{3}\right]$

Volume of the $D H W$ storage tank

$\left[\mathrm{m}^{3}\right]$

Volume of the "intermediate-temperature" storage tank

$\left[\mathrm{m}^{3} / \mathrm{kg}\right]$
Ambient conditions

Electrical energy

Evaporator

Inlet condition

Outlet condition

Thermal energy

\section{Acknowledgements}

This work has been financed by the Research Fund for the Italian Electrical System under the Contract Agreement between RSE S.p.A. and the Ministry of Economic Development - General Directorate for Nuclear Energy, Renewable Energy and Energy Efficiency stipulated on July 29, 2009 in compliance with the Decree of March 19, 2009. The authors are also grateful to CLIVET Spa for elaborating and providing the heat pump employed in the research activities. 


\section{References}

Bai, Y., T. T. Chow, C. Ménézo, and P. Dupeyrat. "Analysis of a Hybrid PV/Thermal Solar-Assisted Heat Pump System for Sports Center Water Heating Application." International Journal of Photoenergy 2012 (2012).

Bakirci, Kadir, and Bedri Yuksel. "Experimental thermal performance of a solar source heat-pump system for residential heating in cold climate region." Applied Thermal Engineering 31 (2011): 1508-1518.

Bridgeman, Andrew, and S. Harrison. "Preliminary experimental evaluations of indirect solar assisted heat pump systems." Proceedings of the 3rd Canadian solar building conference. Fredericton. 2008.

Hepbasli, Arif, and Yildiz Kalinci. "A review of heat pump water heating systems." Renewable and Sustainable Energy Reviews 13 (2009): 1211-1229.

Kamel, Raghad S., Alan S. Fung, and Peter R. H. Dash. "Solar systems and their integration with heat pumps: A review." 87 (2015): 395-412.

Kuang, Y. H., and R. Z. Wang. "Performance of a multi-functional direct-expansion solar assisted heat pump system." Solar Energy 80 (2006): 795-803.

Loose, Anja, Harald Drück, Nadine Hanke, and Frank Thole. "Field Test and Performance Monitoring of Combined Solar Thermal and Heat Pump Systems." ISES Solar World Congress, At Kassel, Germany. 2011.

Ma, Guo-Yuan, and Hui-Xia Zhao. "Experimental study of a heat pump system with flash-tank coupled with scroll compressor." Energy and Buildings 40 (2008): 697-701.

Mohanraj, M., Ye. Belyayev, S. Jayaraj, and A. Kaltayev. "Research and developments on solar assisted compression heat pump systems - A comprehensive review (Part A: Modeling and modifications) ." Renewable and Sustainable Energy Reviews, 2017: In Press

Ozgener, Onder, and Arif Hepbasli. "A review on the energy and exergy analysis of solar assisted heat pump systems." Renewable and Sustainable Energy Reviews 11 (2007): 482-496.

Parida, Bhubaneswari, S. Iniyan, and Ranko Goic. "A review of solar photovoltaic technologies." Renewable and Sustainable Energy Reviews 15 (2011): 1625-1636.

Tian, Y., and C. Y. Zhao. "A review of solar collectors and thermal energy storage in solar thermal applications." Applied Energy 104 (2013): 538-553.

Wang, Qin, Yu-qian Liu, Guo-feng Liang, Jia-rong Li, Shu-fei Sun, and Guang-ming Chen. "Development and experimental validation of a novel indirect-expansion solar-assisted multifunctional heat pump." 43 (2011): 300304.

Zhang, Yaning, Qin Ma, Bingxi Li, Xinmeng Fan, and Zhongbin Fu. "Application of an air source heat pump (ASHP) for heating in Harbin, the coldest provincial capital of China." Energy and Buildings 138 (2017): 96103. 